\title{
The impact of reactive power generation in PV systems on their yearly production of electrical energy
}

\author{
Primož Sukič ${ }^{1}$, Ernest Belič ${ }^{1}$, Mislav Trbušić ${ }^{1}$, Gorazd Štumberger ${ }^{1}$ \\ ${ }^{1}$ University of Maribor \\ Faculty of Electrical Engineering and Computer Science \\ Smetanova 17, 2000 Maribor, Slovenia \\ Phone: +3862220 7056, Fax: +38622525481 \\ e-mail: primoz.sukic@um.si, ernest.belic@um.si, mislav.trbusic@um.si, gorazd.stumberger@um.si
}

\begin{abstract}
.
The paper deals with photovoltaic (PV) systems able to generate reactive power and to curtail active power generation. Based on measurements performed on an existing PV system over 10 years its typical yearly operation profile is determined. It is used to evaluate the ability of the PV system to generate reactive power. After that the efficiency characteristic of a micro-inverter is determined experimentally. It is described as a function of generated active and reactive powers. This function is afterwards used in an optimization procedure, where measured time dependent load and power generation profiles are applied to determine optimal reactive power generation in PV systems installed in an existing low voltage network. Based on calculations performed over one year, the impact of reactive power generation on yearly production of electrical energy in PV systems is evaluated.
\end{abstract}

\section{Key words}

PV systems, micro-inverter, reactive power generation, loss of energy production

\section{Introduction}

The increasing share of photovoltaic (PV) systems and other distributed generation systems influences voltage profile in low voltage distribution networks. In order to further increase the share of PV systems installed in distribution networks, the PV systems should actively contribute to the network operation in the "Smart Grid" manner. This means that the PV systems should be able to generate reactive power or curtail the active power generation according to the given references. In [1] the impact of reactive power generation on low voltage distribution network losses was analyzed. However, the reduction of electrical energy production of PV systems, caused by the reactive power generation was not considered. Some aspects of PV inverter generated reactive power were discussed in [2] where also a costbenefit analysis was performed. The impact of reactive power generation on temperature increase in individual inverter elements, aging of elements and lifetime of the inverter was discussed in [3]. It is pointed out, that due to the reactive power generation, the inverter elements operate more time at higher temperatures, which should also increase the aging of individual elements and reduce the lifetime of the inverter. A similar topic was discussed in [4]. The authors focused on transistor and diode losses caused by increased current values. The losses were determined analytically and by simulation. In [5] it has been shown that the increase of losses caused by reactive power generation in multi-level inverters is strongly dependent on inverter topology. Some of the topics related to reactive power generation in inverters for wind systems were addressed in [6].

In this paper the ability of PV system for reactive power generation is evaluated based on statistical data over 10 years of operation. After that the efficiency characteristic of a micro-inverter for PV systems is determined experimentally. It is given as a function of generated active and reactive powers. An existing low voltage distribution network with PV systems, where further analysis is performed, is described. Given are, date related to its topology, load profiles and profiles of active power generation in PV systems. Based on given data, the optimal reactive power generation is determined for each given time interval. In the optimization procedure, the inverter efficiency characteristics, network topology as well as time dependent load and power generation profiles were considered. At the end the impact of reactive power generation in PV systems on their yearly production of electrical energy is evaluated.

\section{Reactive power generation in PV systems}

The ability of a PV system inverter for reactive power generation is shown in Fig. 1 , where $P$ and $Q$ are the actual inverter generated active and reactive power, respectively, whilst $S_{\max }$ is the rated apparent power of the inverter. With the increasing generation of active power the capability for generation of reactive power decreases. The "grid codes" in some countries require the ability of inverters to generate the active power with a 
certain value of the factor $\cos \varphi$, which is normally $\cos \varphi=0.8$. However, if the inverter is sized in the way that the maximal generated active power $P_{\max }$ equals the rated power $S_{\max }$, the active power generation close to its maximal value must be curtailed to enable operation with $\cos \varphi=0.8$. The question is how much time in a year such conditions might appear. In order to find the answer on this question statistical data of a $7.5 \mathrm{kWp}$ PV system operating since year 2004 were used. An average yearly diagram of its active power generation is shown in Fig. 2.

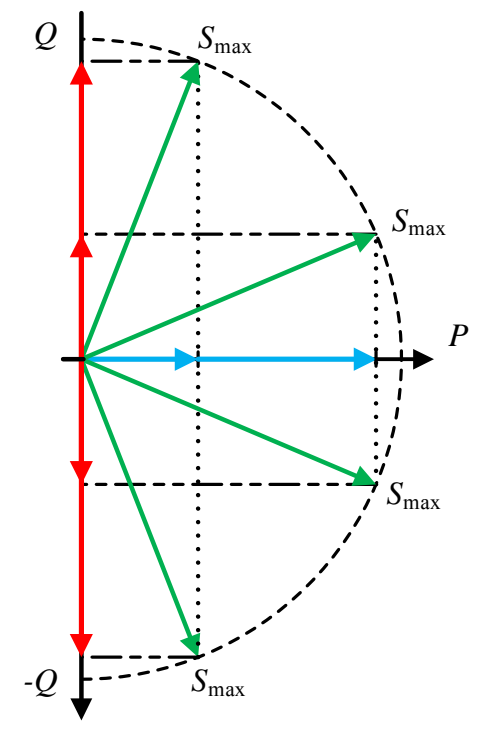

Fig. 1. Capability of the inverter to generate reactive power

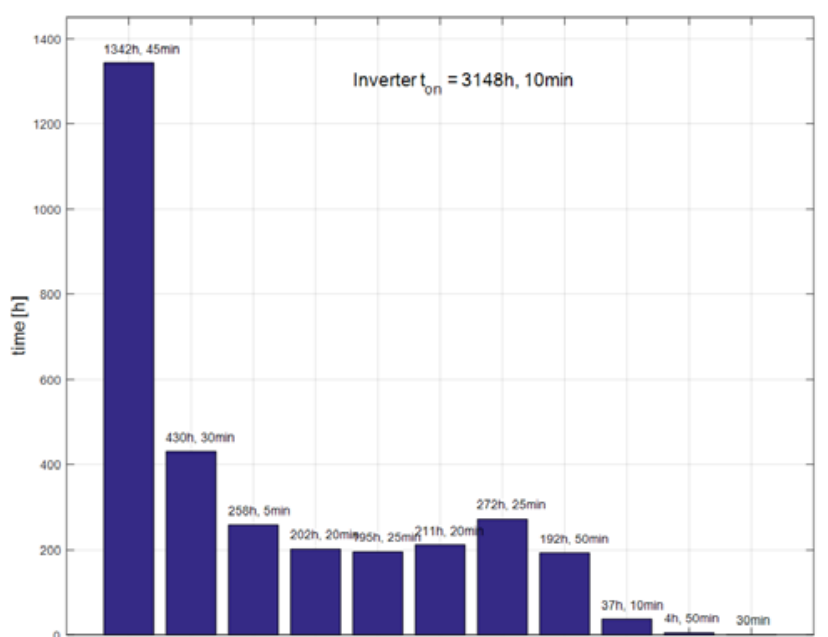

Fig. 2. Average yearly diagram of active power generation

Based on results presented in Fig. 2 and considering Fig. 1 the percentage of the PV system operation time in which the PV system can operate with certain values of $\cos \varphi$ is determined. It is shown in Fig. 3. The results presented in in Fig. 3 clearly show that the discussed PV system could operate with the value of $\cos \varphi=0.8$ in 99.98 percent of the entire operation time in a year without requirements for curtailment of active power generation. Thus, for the discussed PV system, which is sized in the manner that $P_{\max }=S_{\max }$, permanent operation with $\cos \varphi=0.8$ should not be problematical.

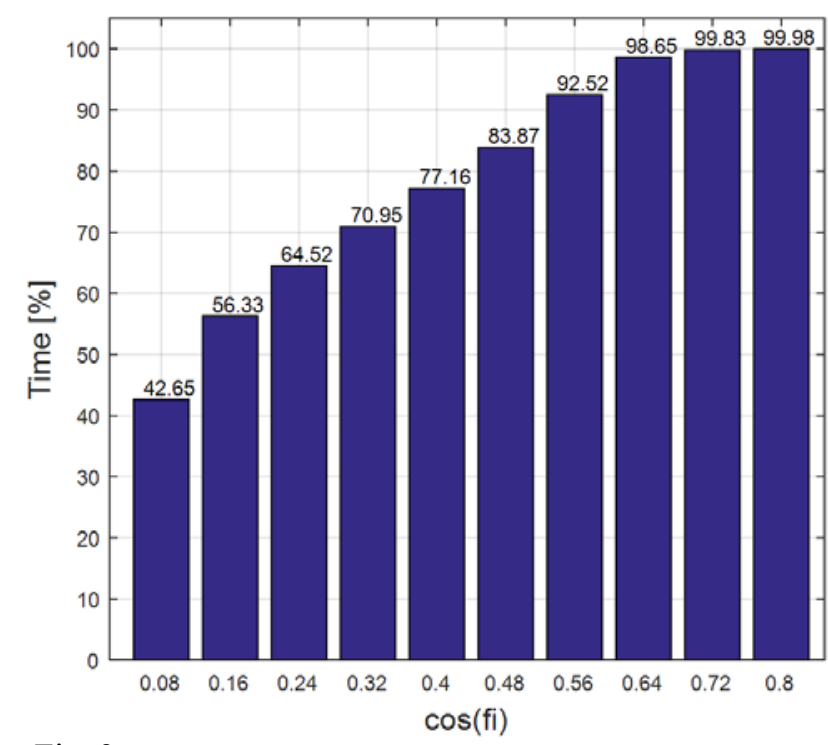

Fig. 3. Percentage of the operation in a year where PV system is capable to operate at different values of $\cos \varphi$

However, the results presented in this section cannot explain what reduction in yearly electrical energy production could be caused by reactive power generation. In order to get a proper answer on this question the inverter efficiency characteristic has to be determined.

\section{Efficiency characteristic of the inverter}

In order to determine the efficiency characteristic a $250 \mathrm{~W}$ micro-inverter was applied as the test object. Its schematic presentation is given in Fig. 4.

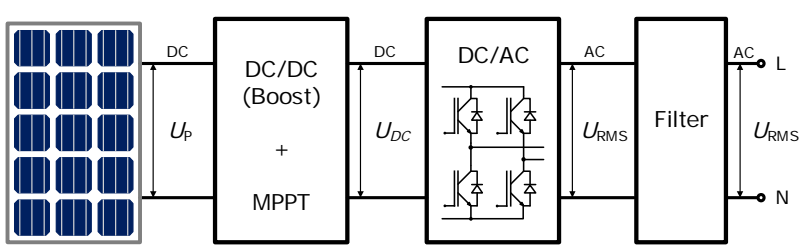

Fig. 4. Schematic presentation of a micro-inverter

The efficiency of micro-inverters is normally lower than the efficiency of string inverters. However, because the micro-inverter is connected to a single PV module, conditioning of the module and the maximum power point tracking should be better than in the case of string inverter where several PV modules are connected in series. The efficiency characteristic obtained by measurements performed on the test micro-inverter is presented in Fig. 5. It is given as a function of generated active power $P$ and reactive power $Q$. It must be pointed out that the efficiency characteristic strongly depends on micro-inverter topology and implemented solutions. Therefore, the presented results must be considered as a case study and cannot be generalized on all microinverters or even inverters for PV systems in general.

The obtained efficiency characteristic is applied to evaluate the impact of reactive power generation in PV systems on the reduction of yearly electricity production. The description of the test distribution network used in the analysis is given in the next section. 


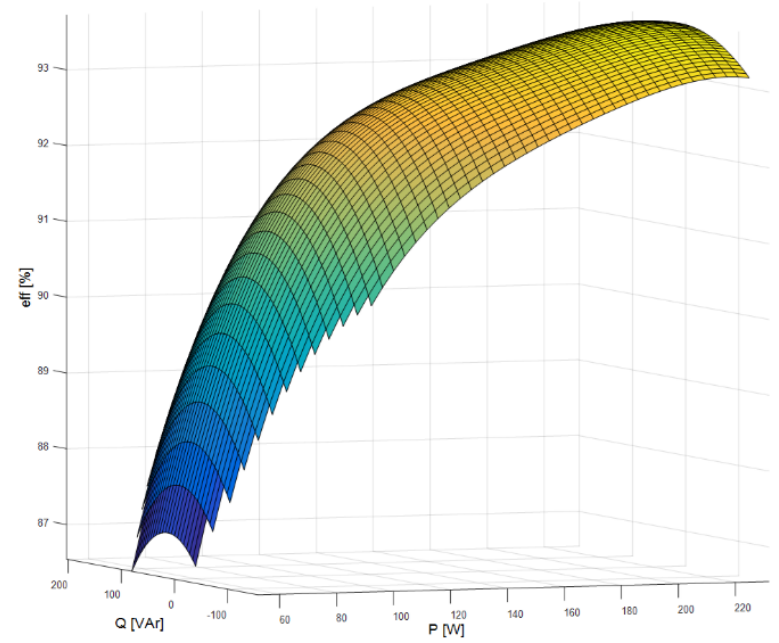

Fig. 5. Efficiency characteristic of the test $250 \mathrm{~W}$ micro-inverter give as a function of the active power $P$ and reactive power $Q$

\section{Network topology and load profiles}

The topology of a real low voltage distribution network used in the analysis is shown in Fig. 6.

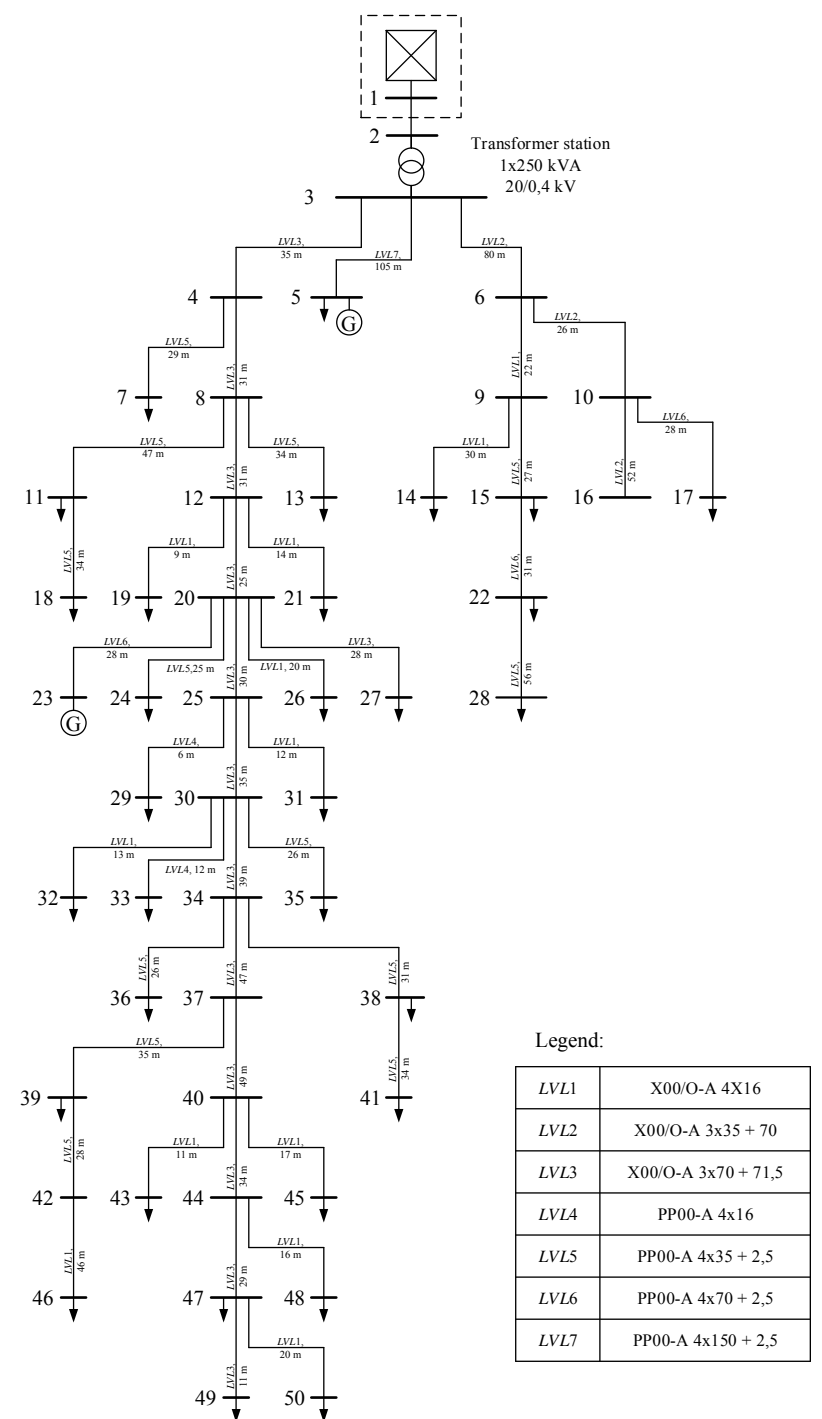

Fig. 6. Schematic presentation of test low voltage distribution network
The test network contains two $50 \mathrm{kWp}$ PV systems connected to the nodes 5 and 23. The peak loading of the network is around $115 \mathrm{~kW}$. It is fed by a $250 \mathrm{kVA}$ transformer Dyn 5, 20kV/0.4 kV, $u_{k}=4.0 \%, P_{F e 0}=0.6$ $\mathrm{kW}$ and $P_{C u 0}=3.25 \mathrm{~kW}$. The load profiles as well as the PV system active power generation profiles were determined by measurements. They are given in hourly intervals over the entire year. Based on this data, average and maximum values are determined for each hour in individual months.

The results are given in the form of time dependent average and maximum daily characteristics for each individual month in the year. The same is valid also for the average and maximum daily PV system generated active power characteristics.

Figs. 7 and 8 show the maximum and average time dependent load profiles for individual months. Similarly, Figs. 9 and 10 show the maximum and average time dependent profiles of PV systems active power generation for individual months.

The micro-inverter efficiency characteristics shown in Fig. 5, the network topology shown in Fig. 6 as well as the load and active power generation profiles shown in Figs. 7 to 10 were applied in differential evolution based optimization procedure, where the optimal reactive power generation in PV systems was determined for each individual hour of profiles shown in Figs. 7 to 10.

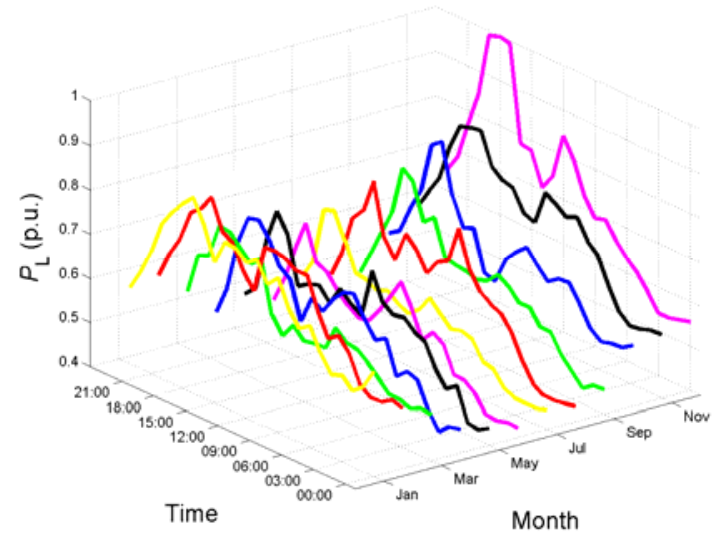

Fig. 7. Time dependent maximum load characteristics for each month in the year

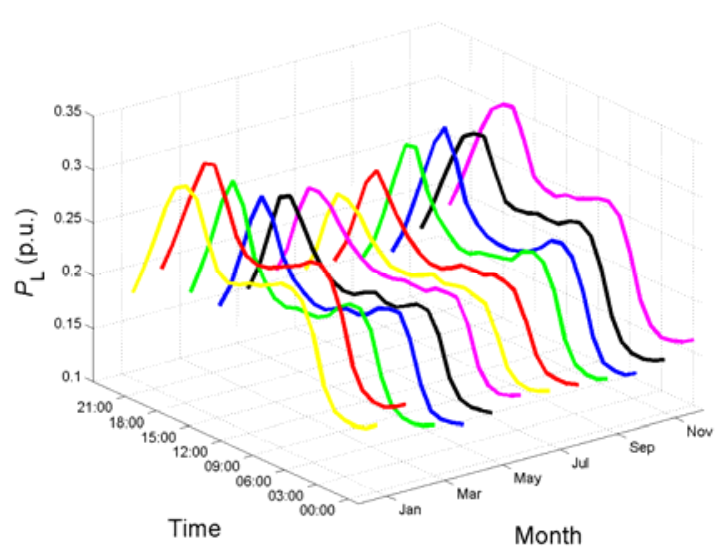

Fig. 8. Time dependent average load characteristics for each month in the year 


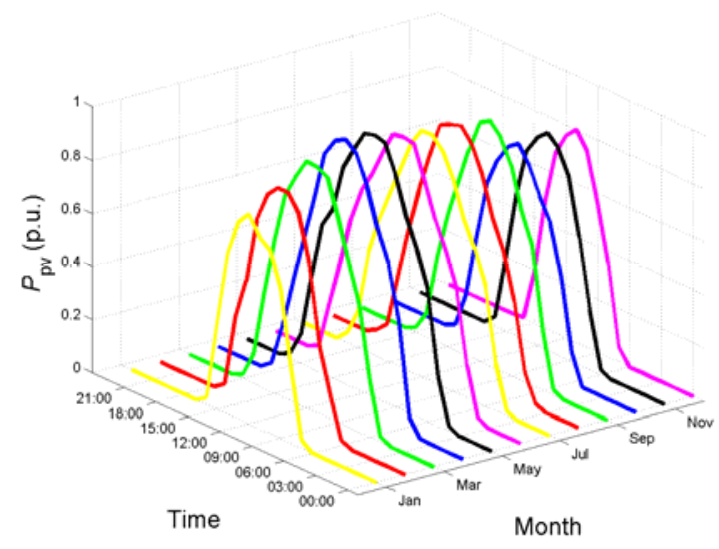

Fig. 9. Time dependent maximum PV system generated active power characteristics for each month in the year

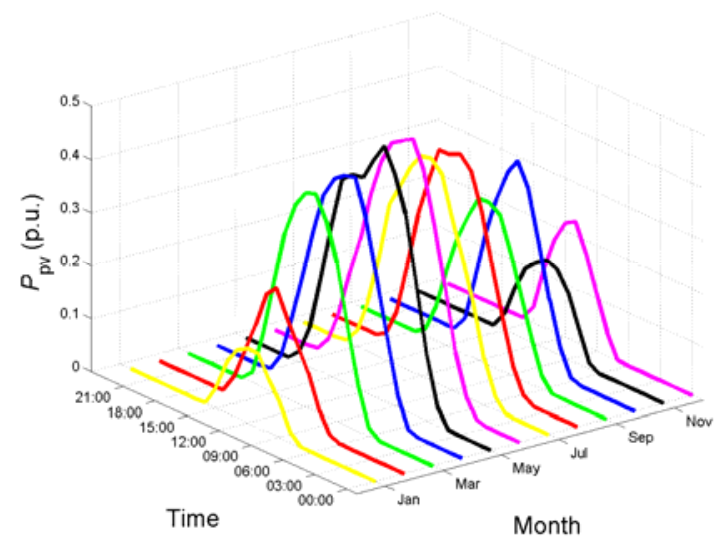

Fig. 10. Time dependent average PV system generated active power characteristics for each month in the year

\section{Results}

Let us first analyze the reduction of network losses that can be achieved in the discussed low voltage distribution network by an optimal generation of reactive power in PV systems. In this case the only optimization goal is the minimization of losses whilst the reduction of active power generation according to the characteristic shown in Fig. 5 is not considered. Thus, the reduction of yearly electrical energy production in PV systems is not discussed in this case. Fig. 11 shows different load profiles that were applied in the analysis.

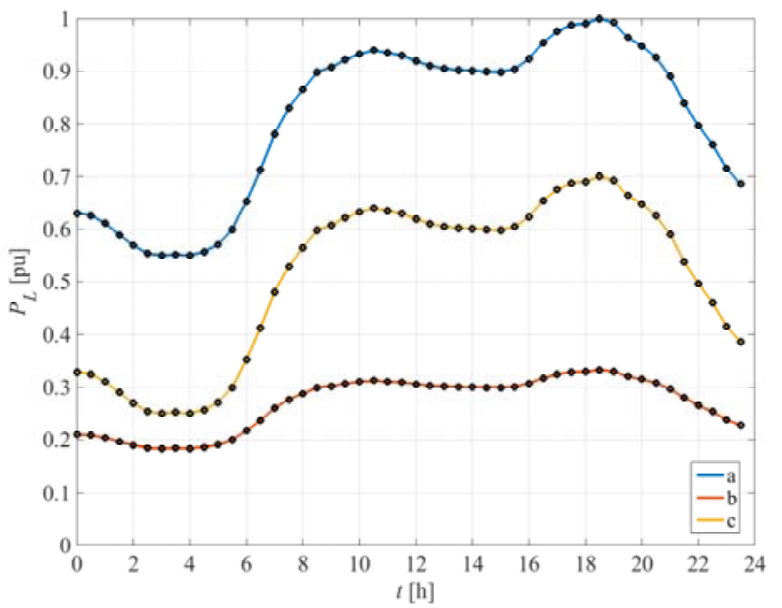

Fig. 11. Different load profiles
Considering the loading profiles a, b and c shown in Fig. 11 , different energy savings achieved by reactive power generation in PV system can be achieved. The total yearly electrical energy consumption $W_{\text {cy }}$ for load profiles a, b and c (Fig. 11) are shown in Table 1 together with the network losses before $W_{\text {loss }}$ and after optimization $W_{\text {loss_opt }}$.

Table 1: Total yearly energy consumption $W_{\text {cy }}$, network losses before optimization $W_{\text {loss }}$ and network losses after optimization $W_{\text {loss opt }}$ for load profiles from Fig. 11

Load profile a, load $\cos \varphi=0.89, W_{\mathrm{cv}}=770,16 \mathrm{MWh}$

\begin{tabular}{|l|l|}
\hline$W_{\text {loss }}=32,23 \mathrm{MWh}$ & $W_{\text {loss opt }}=30,81 \mathrm{MWh}$ \\
\hline
\end{tabular}

Load profile a, load $\cos \varphi=0.95, W_{\mathrm{cy}}=770,16 \mathrm{MWh}$

\begin{tabular}{|l|l|}
\hline$W_{\text {loss }}=28,58 \mathrm{MWh}$ & $W_{\text {loss opt }}=27,85 \mathrm{MWh}$ \\
\hline
\end{tabular}

Load profile $\mathrm{b}$, load $\cos \varphi=0.95, W_{\mathrm{cy}}=256,72 \mathrm{MWh}$

\begin{tabular}{|l|l|}
\hline$W_{\text {loss }}=7,586 \mathrm{MWh}$ & $W_{\text {loss opt }}=7,502 \mathrm{MWh}$ \\
\hline
\end{tabular}

Load profile c, load $\cos \varphi=0.95, W_{\mathrm{cy}}=484,72 \mathrm{MWh}$

\begin{tabular}{|l|l}
$W_{\text {loss }}=14,16 \mathrm{MWh}$ & $W_{\text {loss opt }}=13,83 \mathrm{MWh}$ \\
\hline
\end{tabular}

The results presented in Table 2 show the yearly energy saving $W \mathrm{~s}_{\mathrm{ave}}$ and maximum load power $P_{\mathrm{Lmax}}$ for different load profiles and different $\cos \varphi$. It is clear that the energy saving that can be achieved by the reduction of network losses caused by the reactive power generation on PV systems strongly depend on the load profile and $\cos \varphi$.

Table 2: Yearly energy savings $W \mathrm{~s}_{\text {ave }}$ achieved by PV system reactive power generation for load profiles from Fig. 11 Load profile a, $\operatorname{load} \cos \varphi=0.89$

\begin{tabular}{|l|l|}
\hline$P_{\text {Lmax }}=108.61 \mathrm{~kW}$ & $W \mathrm{~s}_{\mathrm{ave}}=1420 \mathrm{kWh}$ \\
\hline
\end{tabular}

Load profile a, $\operatorname{load} \cos \varphi=0.95$

\begin{tabular}{|l|l|}
\hline$P_{\mathrm{Lmax}}=108.61 \mathrm{~kW}$ & $W \mathrm{~s}_{\mathrm{ave}}=735,97 \mathrm{kWh}$ \\
\hline
\end{tabular}

Load profile $\mathrm{b}, \operatorname{load} \cos \varphi=0.95$

\begin{tabular}{|l|l|}
\hline$P_{\text {Lmax }}=32.20 \mathrm{~kW}$ & $W \mathrm{~s}_{\text {ave }}=84.53 \mathrm{kWh}$ \\
\hline
\end{tabular}

Load profile c, load $\cos \varphi=0.95$

\begin{tabular}{|l|l|}
\hline$P_{\mathrm{Lmax}}=76.03 \mathrm{~kW}$ & $W \mathrm{~s}_{\mathrm{ave}}=323,51 \mathrm{kWh}$ \\
\hline
\end{tabular}

Table 3 shows the results obtained for the network shown in Fig. 6, inverter efficiency characteristics shown in Fig. 5 , average load profiles shown in Fig. 8 and the average PV system active power generation profiles shown in Fig. 10. The optimization was performed in order to minimize losses related to energy transmission in the discussed distribution network. Presented is the reduction of energy losses in the network $W_{\text {Save }}$ as well as the reduction of energy produced in PV systems $W_{\mathrm{PV}}$.

Table 3: Yearly energy savings $W s_{\text {ave }}$ due to the reduction of losses in the network and reduction of PV system energy production

\begin{tabular}{|r|r|r|}
\hline \multicolumn{1}{|c|}{$\cos \varphi$} & $W_{\text {Save }}(\mathrm{kWh})$ & \multicolumn{1}{|c|}{$W_{\mathrm{PV}}(\mathrm{kWh})$} \\
\hline 0.8 & 170,70 & 139.86 \\
\hline 0.9 & 79.75 & 82.92 \\
\hline Measured profile & 49.76 & 63.86 \\
\hline
\end{tabular}

The results presented in Table 2 show that in the case when average load and active power PV generation profiles determined by measurements are applied together with measured efficiency characteristic of the inverter, the reduction of energy losses in the network is in the same range as the reduction of electrical energy production in PV systems where reactive power is generated. 


\section{Conclusion}

According to the "grid codes" in many countries the PV systems are obligated to generate reactive power up to $\cos \varphi=0.8$. However, when the reactive power is generated in PV systems, in order to reduce distribution system losses, the reduction of losses could be in the same range as the reduction of electrical energy production in PV systems. Thus, to properly asses the impact of reactive power generation in PV systems on distribution network losses, an analysis using measured loads and PV systems active power generation profiles is indispensible.

\section{Acknowledgement}

This work was supported in part by the Slovenian Research Agency under research contract L2-5489.

\section{References}

[1]E. Belič, K. Dežan, N. Lukač and G. Štumberger, " Reduction of energy losses achieved by an optimal reactive power generation in photovoltaic systems installed inside a low voltage distribution network, International Conference on Renewable Energies and Power Quality (ICREPQ'15), 2015.

[2] M. Braun, Reactive power supplied by PV invrters - costbenefit anlysis, 22nd European Photovoltaic Solar Energy Conference and Exhibition, 2007.

[3] A. Anurag, Y. Yang and F. Blaabjerg, Impact of reactive power injection outside feed-in hours on the reliability of photovoltaic inverters, IEEE 6th International Symposium on Power Electronics for Distributed Generation Systems (PEDG), 2015.

[4] S. Sreechithra, P. Jirutitijaroen and A. Rathore, Impacts of reactive power injections on thermal performances of PV inverters, IECON 2013 - 39th Annual Conference of the IEEE Industrial Electronics Society, 2013

[5] F. Gervasio, R. Mastromauro and M. Liserre, Power losses analysis of two-levels and three-levels PWM inverters handling reactive power, IEEE International Conference on Industrial Technology (ICIT), 2015.

[6] K. Ma, M. Liserre and F. Blaabjerg, Reactive Power Influence on the Thermal Cycling of Multi-MW Wind Power Inverter, IEEE Transactions on Industry Applications, , pp. 922-930, 2013. 